\title{
Effects of lactational and reproductive status on ovarian follicular waves in llamas (Lama glama)*
}

\author{
G. P. Adams, J. Sumar† and O. J. Ginther \\ University of Wisconsin, Department of Veterinary Science, Madison, Wisconsin 53706, USA; and \\ $\uparrow$ Veterinary Institute for Tropical and High Altitude Research, San Marcos University, Lima, Peru
}

\begin{abstract}
Summary. The effects of lactational status and reproductive status on patterns of follicle growth and regression were studied in 41 llamas. Animals were examined daily by transrectal ultrasonography for at least 30 days. The presence or absence of a corpus luteum and the diameter of the largest and second largest follicle in each ovary were recorded. Llamas were categorized as lactating $(\mathrm{N}=16)$ or non-lactating $(\mathrm{N}=25)$ and randomly allotted to the following groups (reproductive status): (1) unmated (anovulatory group, $\mathrm{N}=14$ ), (2) mated by a vasectomized male (ovulatory nonpregnant group, $\mathrm{N}=12$ ), (3) mated by an intact male and confirmed pregnant (pregnant group, $\mathrm{N}=15$ ). Ovulation occurred on the 2 nd day after mating with a vasectomized or intact male in $26 / 27(96 \%)$ ovulating llamas. Interval from mating to ovulation $(2 \cdot 0 \pm 0.1$ days $)$ and growth rate of the preovulatory follicle $(0.8 \pm 0.2 \mathrm{~mm} /$ day) were not affected by lactational status or the type of mating (vasectomized $v s$ intact male). Waves of follicular activity were indicated by periodic increases in the number of follicles detected and an associated emergence of a dominant follicle that grew to $\geq 7 \mathrm{~mm}$. There was an inverse relationship ( $r=-0 \cdot 2 ; P=0.002)$ between the number of follicles detected and the diameter of the largest follicle. Successive dominant follicles emerged at intervals of $19.8 \pm 0.7$ days in unmated and vasectomy-mated llamas and $14.8 \pm 0.6$ days in pregnant llamas $(P=0.001)$. Lactation was associated with an interwave interval that was shortened by $2.5 \pm 0.05$ days averaged over all groups $(P=0.03)$. Maximum diameter of anovulatory dominant follicles ranged from 9 to $16 \mathrm{~mm}$ and was greater $(P<0.05)$ for non-pregnant llamas (anovulatory group, $12.1 \pm 0.4 \mathrm{~mm}$; ovulatory group, $11.5 \pm 0.2 \mathrm{~mm}$ ) than for pregnant llamas $(9 \cdot 7 \pm 0.2 \mathrm{~mm})$. In addition, lactation was associated with smaller $(P<0.05)$ maximum diameter of dominant follicles averaged over all reproductive statuses $(10 \cdot 4 \pm 0 \cdot 2$ vs $11.7 \pm 0.3 \mathrm{~mm})$. The corpus luteum was maintained for a mean of 10 days after ovulation in non-pregnant llamas and to the end of the observational period in pregnant llamas. The presence (ovulatory non-pregnant group) and persistence (pregnant group) of a corpus luteum was associated with a depression in the number of follicles detected and reduced prominence of dominant follicles (anovulatory group $>$ ovulatory non-pregnant group $>$ pregnant group). Lactation was also associated with reduced prominence of dominant follicles. The results demonstrate that follicular activity occurred in waves for llamas of all types of reproductive status and that lactation and the presence of a corpus luteum were associated with depressed follicular development.
\end{abstract}

Keywords: ovaries; follicles; follicular waves; lactation; llamas; camelids

*Reprint requests to $\mathrm{O}$. J. Ginther. 


\section{Introduction}

The llama (Lama glama) is a domesticated member of the 4 species of New World camelids. The other species are the domestic alpaca (Lama pacos), and 2 wild species, the vicuna (Lama vicugna), and guanaco (Lama guanicoe). Related Old World camelids include the dromedary (1-humped) and bactrian (2-humped) camels. Oestrus in camelids may continue for several weeks with ovulation occurring only after the female is mated (induced ovulation; Novoa, 1970). The phenomenon of induced ovulation has been demonstrated in llamas (England et al., 1969) and alpacas (San Martin et al., 1968; Fernandez-Baca et al., 1970), and in dromedary (Shalash \& Nawito, 1964; Musa \& Abusineina, 1978) and bactrian (Chen \& Yuen, 1979) camels. Lactational status, as well as reproductive status, affects ovarian activity; in all mammals studied, lactation is associated with decreased follicular development (Greenwald \& Terranova, 1988). This phenomenon has been shown in spontaneous ovulators (e.g., cow: Short et al., 1972; mare: Ginther, 1979; pig: Cox \& Britt, 1982) as well as induced ovulators (cat: Schmidt et al., 1983; rabbit: Colby, 1986). However, the effects of reproductive status and lactational status on follicular growth and regression in camelids apparently have not been reported. Transrectal ultrasonography has been used to characterize waves of follicular activity in the ovaries of mares (Pierson \& Ginther, 1987; Sirois et al., 1989) and heifers (Savio et al., 1988; Sirois \& Fortune, 1988; Knopf et al., 1989). Follicular waves involve the synchronous emergence of several follicles, one of which becomes dominant. In heifers, most oestrous cycles have 2 (Ginther et al., 1989a) or 3 (Savio et al., 1988; Sirois \& Fortune, 1988) waves of follicular activity. Waves occur at regular intervals until the corpus luteum regresses (nonpregnant heifers). In the absence of luteal regression (pregnant heifers) periodic follicular emergence continues (Ginther et al., 1989b). Ultrasonically detected changes in the in-situ morphology of the ovaries, uterus and cervix in llamas have been described (Adams et al., 1989), but no reference was found to the occurrence of follicular waves in any member of the family Camelidae.

The purpose of the present study was to characterize patterns of follicular growth and regression in llamas and to determine the effects of lactational status (lactating, non-lactating) and reproductive status (anovulatory, ovulatory non-pregnant, pregnant) on follicular patterns.

\section{Materials and Methods}

Female llamas $(\mathrm{N}=74)$ ranging in age from 2 to 11 years and weighing $79-137 \mathrm{~kg}$ were used during the rainy season (February-April) in the Andes Mountains (altitude, $4200 \mathrm{~m}$ ) at Centro Experimental LaRaya in Peru. On the basis of an initial transrectal ultrasonic examination, the llamas were selected from a group of approximately 250 using the following criteria: (1) non-pregnant, (2) adequate size to accommodate transrectal examination, and (3) no apparent pathological conditions of the reproductive tract. The llamas were grouped as lactating or non-lactating and then randomly allotted to the following mating groups: (1) unmated $(\mathrm{N}=25)$, (2) mated with a vasectomized male $(\mathrm{N}=21)$, and (3) mated with an intact male $(\mathrm{N}=28)$. The day of mating was chosen on the basis of the following criteria: $\geq 10$ days post partum, no detectable corpus luteum, and 1 or more follicles $7-12 \mathrm{~mm}$ in diameter which had increased in size from the previous day (Adams et al., 1989). The day of mating was based on the ultrasonic appearance of the ovaries, rather than behavioural receptivity to a male, to minimize the introduction of confounding stimuli which may have affected follicle growth and ovulation in the unmated group. For the same reason, llamas in the 2 mated groups were mated in an enclosure with solid walls. Two uninterrupted matings, 4-8 h apart, were allowed. Four vasectomized males and 6 intact males were used; the same male was used for both matings of an individual female. Males were not used for more than 2 matings ( 1 female) per day.

Before data inspection and analysis, 41 llamas were selected from the 3 mating groups using the following criteria: (1) all groups: lactational status did not change during the experimental period, (2) unmated group: ovulation did not occur, (3) mated with a vasectomized male: ovulation occurred, (4) mated with an intact male: pregnancy occurred, and (5) all groups: haemorrhagic follicles did not develop. Haemorrhagic follicles in mares have been described as unusually large, blood-filled structures which are ultrasonically detectable for a prolonged period (Ginther \& Pierson, 1984). The remaining 33 llamas were excluded as follows: spontaneous ovulation in the unmated group $(2$ of $25,8 \%)$, ovulation failure in the mated groups ( 5 of $49,10 \%$ ), non-pregnant in the intact-mated group ( 7 of $28,25 \%$ ), cessation of lactation during the observational period $(8$ of $24,33 \%$ ), and development of apparent haemorrhagic follicles (11 of $52,21 \%$ ). After these preplanned exclusions, data from 41 llamas were available and were grouped by lactational status and reproductive status as indicated in Table 3. 
Transrectal ultrasonic examinations of the reproductive tract were done by a single operator using a real-time, B-mode scanner (Aloka 210 DX, Corometrics Medical Systems Inc., Wallingford, CT, USA) equipped with a $5 \cdot 0$ or $7.5 \mathrm{MHz}$ linear-array transducer. Ovarian and uterine structures were ultrasonically identified as described (Adams $e t$ al. 1989). Llamas in the unmated group (anovulatory) were examined once daily for a minimum of 30 days. Llamas in the mated groups were examined once daily for at least 10 days before and 29 days after ovulation. During each examination, the presence or absence of a corpus luteum was noted and the vertical diameter of the largest and second largest follicle in each ovary was recorded. The minimum and maximum number of recorded follicles per llama per examination were 0 and 4 , respectively. Ovulation (Day 0 ) in the mated groups was defined as the disappearance of a large ( $\geq 7 \mathrm{~mm}$ ) follicle that was present on the previous day and confirmed by the subsequent detection of a corpus luteum (Adams et al., 1989). Pregnancy was defined as the ultrasonic detection of an embryo proper and embryonic heartbeat.

No attempt was made during the examinations to identify individual follicles sequentially. A day-to-day growth and regression profile of the largest follicle (ignoring individual identity) was plotted for each llama. Inspection of data with consideration of location (left $v s$ right ovary) and diameters on succeeding days convincingly indicated that when the largest follicle reached $7 \mathrm{~mm}$ the prior follicular diameter profile had depicted the same individual follicle. Therefore, a dominant follicle was defined as one that grew to at least $7 \mathrm{~mm}$ and exceeded the diameter of all other follicles. To determine whether follicular activity occurred in waves, the number of detected follicles in both ovaries for each day was tabulated in relation to the diameter of the largest follicle; the day the largest follicle first reached maximum diameter was used as the common reference point for all 3 reproductive status conditions because the day of ovulation was not available in the anovulatory group. The mean number of follicles per day from 12 days before to 17 days after the reference point was examined. If differences within days occurred at apparent regular intervals for a given group, the follicular pattern was defined as wave-like. The correlation between follicle numbers and diameter of the largest follicle over days was calculated on the combined data. An inverse relationship, wherein number of follicles decreased as the diameter of the largest follicle increased, was taken as further indication of the presence of follicular waves. That is, emergence of a group of small follicles and subsequent growth of one follicle to large size while the others regressed would be characteristic of a wave as described for cattle (Ginther et al., 1989a).

To identify wave-like patterns of follicular development further, the growth profile of the dominant follicle was initially plotted and studied in individual animals. Llamas were then categorized into those with successive dominant follicles in contralateral ovaries and those with successive dominant follicles in ipsilateral ovaries. In the contralateral category, successive dominant follicles were clearly distinguishable from each other, including, for most follicles, much of the growing and regressing phases. Data from the contralateral category were used to identify the separation between dominant follicles in the ipsilateral category. The deviations in the follicle diameter profile of individual dominant follicles in the contralateral group exceeded 2 standard deviations from the average of all deviations in only 2 of 37 observations, and none exceeded 3 standard deviations. Such deviations were attributed to measuring errors. Deviations in profile for diameter of the largest follicle in the ipsilateral group that exceeded 4 standard deviations from the mean for the contralateral group were assumed to represent the regressing phase of one follicle and the growing phase of the next follicle. No differences in the resulting individual follicular profiles were found between the contralateral and ipsilateral categories, indicating that individual dominant follicles were satisfactorily identified in the ipsilateral category; therefore, the data were combined.

The above approach indicated that follicular activity occurred in periodic waves. The follicular waves were classified as the preovulatory wave (mated groups only), Wave 1 and Wave 2 . The preovulatory wave involved the dominant follicle that ovulated and Waves 1 and 2 involved the first and second dominant anovulatory follicles detected during the observational period. Effects of lactational status and reproductive status on the following end points were examined: (1) interval (days) from mating to ovulation, (2) growth rate of the preovulatory follicle from Day -10 to Day $-I$ and from the day of mating to Day -1 , (3) follicle diameter on the day before ovulation, (4) day the dominant follicle was first detected, (5) interval (days) between detection of successive dominant follicles (interwave interval), (6) day the corpus luteum was first detected, (7) day the corpus luteum was last detected, (8) maximum follicle diameter of Waves 1 and 2 (Wave 2 was deleted in 18 (44\%) llamas in which the observational period did not extend to the time of apparent maximal size of the dominant follicle), and (9) day-to-day follicular growth and regression profiles of the dominant follicles. By retrospection, the dominant follicle was first identified at $3-4 \mathrm{~mm}$ in diameter in $47 / 57(82 \%)$ of follicular waves in which it could be determined. The mean day of first detection of the dominant follicle of each wave (Table 1) was used to assign the wave to a day scale and was used as a common starting point to generate day to day mean diameter profiles of the dominant follicles (Figs 2 \& 3). For individuals whose dominant follicle was first detected at a diameter larger than $4 \mathrm{~mm}$, the starting day was extrapolated by using the overall mean follicle growth rate $(0.8 \mathrm{~mm} /$ day $)$. The growth profile of preovulatory follicles of mated llamas was normalized to the day of ovulation. The effect of follicle size at mating on interval from mating to ovulation and on preovulatory follicle growth rate from the day of mating to Day -1 was determined. For comparative purposes, Wave 1 of the anovulatory group was plotted to begin on the same day as Wave 1 of the ovulatory groups. To present a visual concept of the continuous nature of the follicular profiles, regression lines were used to characterize the means.

Statistical procedures involved analyses of variance to test for differences within or, when appropriate, among main effects and their interactions. Split-plot designs were used to account for hierarchical classifications (Gill \& Hafs, 1971) using the general linear model of the Statistical Analysis System (SAS User's Guide, 1985). Multiple comparisons were made by the method of least significant difference if statistical significance (main effects or interactions) was reached in the overall analyses. 


\section{Results}

There were main effects of reproductive status $(P<0.0001)$ and day $(P<0.0001)$, but not lactational status or any of the interactions on the number of follicles detected from 12 days before to 17 days after the largest follicle reached maximum diameter. Averaged over days, the number of follicles detected was greatest for anovulatory llamas $(2 \cdot 1)$, intermediate for ovulatory nonpregnant llamas (1.4) and least for pregnant llamas (1.2) (1sd $=0.1, P<0.05$ among all groups). There was a negative correlation $(r=-0 \cdot 2 ; P=0.002)$ between the number of follicles detected and the diameter of the largest follicle (Fig. 1).

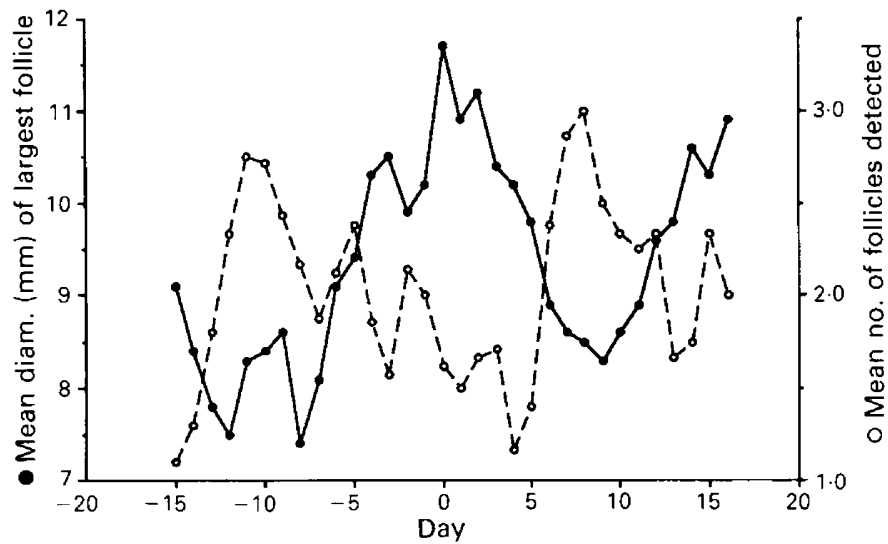

Fig. 1. Inverse relationship $(r=-0 \cdot 2 ; P=0.002)$ between the number of follicles detected and the diameter of the largest follicle in llamas. Day $0=$ day the largest follicle first reached maximum diameter. $\mathrm{N}=5-14$ per day; s.e.m. for follicle numbers/day ranged from $0 \cdot 1$ to 0.8 ; s.e.m. for follicle diameter/day ranged from 0.4 to $1 \cdot 3$.

For ovulatory llamas (mated groups), there were no significant main effects of lactational or reproductive status nor a lactation by reproductive status interaction for any of the following end points: (1) interval from mating to ovulation, (2) growth rate of the preovulatory follicle from Day -10 to Day -1 and from the day of mating to Day -1 , (3) diameter of the preovulatory follicle on the day before ovulation, and (4) day of first detection of the dominant follicle of Wave 1 (Table 1). The interval from mating to ovulation was not affected by the follicle size at the time of mating; however, the mean follicle growth rate from mating to ovulation was greater $(P=0.02)$ for follicles 7-9 mm diameter than for those $10-12 \mathrm{~mm}$ diameter at the time of mating (Table 2).

Averaged over all reproductive status conditions, the interwave interval was 2.5 days shorter $(P=0.03)$ for lactating than for non-lactating llamas (Table 3). There was also an overall effect $(P=0.001)$ of reproductive status on interwave interval, attributable to a shorter interval for pregnant llamas than for anovulatory and ovulatory non-pregnant llamas (Table 3). There was no lactational status by reproductive status interaction on interwave interval. For ovulatory llamas, there was a lactational status by reproductive status interaction $(P=0.03)$ for the day of first detection of the corpus luteum; the interaction was attributable to a delay in lactating pregnant llamas compared to llamas of all other status conditions (Table 3 ). The corpus luteum was detected for a shorter time $(P<0.001)$ in non-pregnant than in pregnant llamas (Table 3$)$. The corpus luteum was detected throughout the observational period in all pregnant llamas. There was no lactational status effect or a lactational by reproductive status interaction on the day of last detection of the corpus luteum. The maximum diameter attained by the dominant follicles of anovulatory waves (combined for Waves 1 and 2$)$ was smaller $(P=0.05)$ for lactating llamas than for non-lactating llamas (Table 3). The maximum follicle diameter (combined for Waves 1 and 
Table 1. Interval from mating to ovulation, growth rate of the preovulatory follicle, preovulatory follicle size, and the day of detection of the dominant follicle in llamas

\begin{tabular}{|c|c|c|c|}
\hline & \multicolumn{2}{|c|}{ Reproductive status } & \multirow[b]{2}{*}{ Total } \\
\hline & $\begin{array}{c}\text { Ovulatory } \\
\text { non-pregnant } \\
\text { (vasectomy-mated) }\end{array}$ & $\begin{array}{c}\text { Ovulatory } \\
\text { pregnant } \\
\text { (intact-mated) }\end{array}$ & \\
\hline \multicolumn{4}{|c|}{ Interval from mating to ovulation (days) } \\
\hline $\begin{array}{l}\text { Non-lactating } \\
\text { Lactating }\end{array}$ & $\begin{array}{ll}2 \cdot 0 \pm 0.0 & (6) \\
2 \cdot 2 \pm 0 \cdot 2 & (6)\end{array}$ & $\begin{array}{l}2 \cdot 0 \pm 0.0 \\
2 \cdot 0 \pm 0.0\end{array}$ & $\begin{array}{l}2 \cdot 0 \pm 2 \cdot 0 \quad(15) \\
2 \cdot 1 \pm 0 \cdot 1 \quad(12)\end{array}$ \\
\hline Total & $2 \cdot 1 \pm 0 \cdot 1$ & $2 \cdot 0 \pm 0 \cdot 0 \quad(15)$ & $2 \cdot 0 \pm 0 \cdot 1$ \\
\hline \multicolumn{4}{|c|}{ Follicle growth rate $(\mathrm{mm} / \mathrm{day})(\mathrm{Day}-10 \text { to Day }-1)^{*}$} \\
\hline Non-lactating & $0.8 \pm 0.13$ & $0.8 \pm 0.07$ & $0.8 \pm 0.06(15)$ \\
\hline Lactating & $0.7 \pm 0.07$ & $0.7 \pm 0.07$ & $0.7 \pm 0.05(12)$ \\
\hline Total & $0.7 \pm 0.07(12)$ & $0.8 \pm 0.05(15)$ & $0.8 \pm 0.04(27)$ \\
\hline \multicolumn{4}{|c|}{ Follicle growth rate $(\mathrm{mm} / \mathrm{day})$ (Day of mating to Day -1$)^{*}$} \\
\hline Non-lactating & $0.0 \pm 0.4$ & $0.6 \pm 0.3$ & $0.4 \pm 0.2 \quad(15)$ \\
\hline Lactating & $0.7 \pm 0.4$ & $0.5 \pm 0.2$ & $0.6 \pm 0.2 \quad(12)$ \\
\hline Total & $0.3 \pm 0.3 \quad(12)$ & $0.6 \pm 0.2$ & $0.5 \pm 0.2$ \\
\hline \multicolumn{4}{|c|}{ Follicle diameter on day before ovulation $(\mathrm{mm})$} \\
\hline Non-lactating & $9 \cdot 0 \pm 0.6$ & $10 \cdot 4 \pm 0 \cdot 6$ & $9 \cdot 8 \pm 0.4 \quad(15)$ \\
\hline Lactating & $9 \cdot 8 \pm 0.4 \quad(6)$ & $10 \cdot 3 \pm 0 \cdot 5$ & $10 \cdot 1 \pm 0 \cdot 3(12)$ \\
\hline Total & $9.4 \pm 0.4 \quad(12)$ & $10.4 \pm 0.4$ & $10 \cdot 0 \pm 0 \cdot 3$ \\
\hline \multicolumn{4}{|c|}{ Day dominant follicle first detected* } \\
\hline Non-lactating & $3.0 \pm 0.6 \quad(6)$ & $2 \cdot 8 \pm 0.4$ & $2 \cdot 9 \pm 0 \cdot 3(15)$ \\
\hline Lactating & $3.0 \pm 0.4$ & $2 \cdot 7 \pm 0.5 \quad(6)$ & $2.8 \pm 0.3$ (12) \\
\hline Total & $3 \cdot 0 \pm 0.3$ & $2 \cdot 8 \pm 0.3$ & $2 \cdot 9 \pm 0.2$ \\
\hline
\end{tabular}

Values are mean \pm s.e.m. for the no. of animals indicated.

For all end points, the main effects of lactational status and reproductive status and their interaction were not significant.

*Day $0=$ ovulation. Follicle growth rate from day of mating to Day -1 was slower $(P<0.001)$ than that for Day -10 to Day $-1(0.5$ vs $0.8 \mathrm{~mm} /$ day $)$.

Table 2. Effect of follicle diameter at mating on interval to ovulation and follicle growth rate

\begin{tabular}{|c|c|c|c|c|c|c|}
\hline \multirow[b]{2}{*}{ End point } & \multicolumn{6}{|c|}{ Follicle diameter at mating $(\mathrm{mm})$} \\
\hline & 7 & 8 & 9 & 10 & 11 & 12 \\
\hline No. of llamas & 1 & 7 & 8 & 6 & 3 & 2 \\
\hline $\begin{array}{l}\text { Interval, mating to } \\
\text { ovulation (days) }\end{array}$ & $2 \cdot 0 \pm 0 \cdot 0$ & $2 \cdot 1 \pm 0 \cdot 1$ & $2 \cdot 0 \pm 0 \cdot 0$ & $2 \cdot 0 \pm 0 \cdot 0$ & $2 \cdot 0 \pm 0 \cdot 0$ & $2 \cdot 0 \pm 0 \cdot 0$ \\
\hline $\begin{array}{l}\text { Follicle growth rate fro } \\
\text { mating to Day }-1 \\
(\mathrm{~mm} / \text { day })^{*}\end{array}$ & $1 \cdot 0 \pm 0 \cdot 0$ & $1 \cdot 0 \pm 0.3$ & $0.6 \pm 0.3$ & $0 \cdot 1 \pm 0.2$ & $0.2 \pm 0.7$ & $-0.3 \pm 0.5$ \\
\hline
\end{tabular}

Values are mean \pm s.e.m.

No significant effect on interval to ovulation or follicle growth rate.

* Mean for follicles $7-9 \mathrm{~mm}(0 \cdot 8 \pm 0 \cdot 2)$ was greater $(P=0 \cdot 02)$ than for follicles $10-12 \mathrm{~mm}(0 \cdot 1 \pm 0 \cdot 2)$. 
2) was smaller $(P<0.05)$ for pregnant llamas than for anovulatory and non-pregnant llamas. There was a reproductive status by wave interaction $(P=0.004)$ on maximum follicle diameter attributable to a wave effect $(P<0 \cdot 05)$ only in pregnant llamas (Table 3$)$.

Table 3. Effect of lactational status and reproductive status on interwave interval, detection of the corpus luteum, and maximum diameter of the dominant follicle during Waves 1 and 2

\begin{tabular}{|c|c|c|c|c|}
\hline & \multicolumn{3}{|c|}{ Reproductive status } & \multirow[b]{2}{*}{ Total } \\
\hline & $\begin{array}{l}\text { Anovulatory } \\
\text { (not mated) }\end{array}$ & $\begin{array}{c}\text { Ovulatory } \\
\text { non-pregnant } \\
\text { (vasectomy-mated) }\end{array}$ & $\begin{array}{c}\text { Ovulatory } \\
\text { pregnant } \\
\text { (intact-mated) }\end{array}$ & \\
\hline \multicolumn{5}{|c|}{ Interval (days) between the emergence of successive dominant follicles (interwave interval) $\dagger$} \\
\hline Non-lactating & $20 \cdot 9 \pm 1 \cdot 6(10)$ & $21 \cdot 4 \pm 1 \cdot 4(6)$ & $15 \cdot 2 \pm 0.7$ & $19 \cdot 0 \pm 0.7(25)^{x}$ \\
\hline Lactating & $17.6 \pm 1.9$ & $18 \cdot 0 \pm 1 \cdot 3(6)$ & $14 \cdot 2 \pm 1 \cdot 1 \quad(6)$ & $16.5 \pm 0.8(16)^{y}$ \\
\hline Total & $19 \cdot 9 \pm 1 \cdot 1(14)^{2}$ & $19 \cdot 7 \pm 1.0(12)^{\mathrm{a}}$ & $14.8 \pm 0.6(15)^{b}$ & $18 \cdot 0 \pm 0.5(41)$ \\
\hline \multicolumn{5}{|c|}{ Day corpus luteum first detected (Day $0=$ ovulation) $\ddagger$} \\
\hline Non-lactating & - & $2 \cdot 6 \pm 0.4(6)^{a}$ & $2 \cdot 0 \pm 0.3 \quad(9)^{\mathrm{a}}$ & $2 \cdot 2 \pm 0 \cdot 2(15)^{x}$ \\
\hline Lactating & - & $3.3 \pm 0.5(6)^{2}$ & $5.0 \pm 0.9(6)^{b}$ & $4 \cdot 2 \pm 0.5(12)^{y}$ \\
\hline Total & - & $3 \cdot 0 \pm 0 \cdot 3(12)$ & $3 \cdot 2 \pm 0 \cdot 4(15)$ & $3 \cdot 1 \pm 0 \cdot 2(27)$ \\
\hline \multicolumn{5}{|c|}{ Day corpus luteum last detected (Day $0=$ ovulation) $\S$} \\
\hline Non-lactating & - & $9.6 \pm 0.2$ & $30 \cdot 0 \pm 0 \cdot 2$ & $22 \cdot 6 \pm 0 \cdot 1(15)$ \\
\hline Lactating & - & $10.0 \pm 0.4$ & $29.2 \pm 0.2 \quad(6)$ & $18 \cdot 7 \pm 0.2(12)$ \\
\hline Total & - & $9.8 \pm 0.2(12)^{\mathrm{a}}$ & $29 \cdot 6 \pm 0 \cdot 1(15)^{b}$ & $20 \cdot 9 \pm 0 \cdot 1(27)$ \\
\hline \multicolumn{5}{|c|}{ Maximum diameter of dominant follicle $\uparrow(\mathrm{mm})$} \\
\hline Non-lactating & $12 \cdot 9 \pm 0.5 \quad(7)$ & $11 \cdot 8 \pm 0.8$ & $10 \cdot 3 \pm 0.5 \quad(6)$ & $11 \cdot 7 \pm 0.3(17)^{x}$ \\
\hline Lactating & $10.8 \pm 0.5$ & $11 \cdot 2 \pm 0 \cdot 3$ & $9 \cdot 1 \pm 0.3$ & $10 \cdot 4 \pm 0.2(15)^{y}$ \\
\hline Total & $12 \cdot 1 \pm 0 \cdot 4(\mathrm{I} 1)^{\mathrm{a}}$ & $11.5 \pm 0.2(10)^{a}$ & $9 \cdot 7 \pm 0.2(11)^{b}$ & $11 \cdot 1 \pm 0.2(32)$ \\
\hline Wave $1^{*}$ & $12.1 \pm 0.6(14)^{a . b}$ & $11 \cdot 3 \pm 0.5(12)^{b}$ & $10.3 \pm 0.5(15)^{\mathrm{c}}$ & $11 \cdot 3 \pm 0 \cdot 3(41)$ \\
\hline Wave $2^{*}$ & $12 \cdot 1 \pm 0.7(8)^{\mathrm{a}}$ & $11.6 \pm 0.5(8)^{a, b}$ & $9.1 \pm 0.4(7)^{d}$ & $10 \cdot 7 \pm 0.3(23)$ \\
\hline Total & $12 \cdot 1 \pm 0.4(22)$ & $11 \cdot 4 \pm 0.4(20)$ & $9 \cdot 9 \pm 0 \cdot 3(22)$ & $11 \cdot 1 \pm 0 \cdot 2(64)$ \\
\hline
\end{tabular}

Values are mean \pm s.e.m. $(\mathrm{N})$.

$\dagger$ Lactational status effect, $P=0.03$. Reproductive status effect, $P=0.001$. Interaction, not significant.

$\ddagger$ Lactational status effect, $P=0.0008$. Reproductive status effect, not significant. Interaction, $P=0.03$.

$\S$ Lactational status effect, not significant. Reproductive status effect, $P=0.0001$. Interaction, not significant.

- Lactational status effect, $P=0 \cdot 05$. Reproductive status effect, not significant. Wave effect, not significant. Reproductive status by wave interaction, $P=0.004$. All other interactions, not significant.

a,b,c,d Within each end point means with different superscripts are different $(P<0.05)$.

${ }^{x}, y$ Within lactational status means with different superscripts are different $(P<0.05)$.

*Data were combined for lactational status conditions, therefore $(\mathrm{N})$ represents the number of observations for each wave.

The diameter profiles of the dominant follicle of the preovulatory wave and Waves 1 and 2 are illustrated in Figs 2 and 3. The diameter of the preovulatory follicle from Day -10 to Day -1 was affected by day $(P=0.0001)$ but not by lactational status (Fig. 2 ) or reproductive status (Fig. 3 ). Interactions were not significant. The mean follicle growth rate from the day of mating to Day -1 was lower $(P<0.001)$ than for Day -10 to Day $-1(0.5$ vs $0.8 \mathrm{~mm} /$ day; Table 1$)$. The growth and regression profile of the dominant follicle of Wave 1 was affected by day $(P=0.0001)$, lactational status (Fig. 2; $P=0.03$ ), and reproductive status ( $P=0.03$; Fig. 3). There was no 2-way interaction of lactational and reproductive status, nor a 3-way interaction of these factors with day; therefore, for illustrative purposes, the data were combined for lactational status (Fig. 2) and for reproductive status (Fig. 3). The mean follicle diameter for Wave 1 was smaller $(P<0.05)$ averaged over all days for lactating llamas $(7.9 \pm 0.2 \mathrm{~mm})$ than for non-lactating llamas 
$(8.9 \pm 0.1 \mathrm{~mm})$. The mean diameter was smaller $(P<0.05)$ for pregnant llamas $(7 \cdot 7 \pm 0.2 \mathrm{~mm})$ than for ovulatory non-pregnant llamas $(8.4 \pm 0.2 \mathrm{~mm})$, which in turn was smaller $(P<0.05)$ than for anovulatory llamas $(9.3 \pm 0.2 \mathrm{~mm})$. The mean diameter of the preovulatory follicle increased in a simple linear fashion for non-pregnant (vasectomy-mated) and pregnant (intact-mated) llamas (Fig. 3). The mean diameter of the dominant follicle of Wave 1 followed a quadratic profile in all groups (Figs 2 and 3). Additional coefficients of higher order polynomial expression did not significantly contribute to the fit of the data.

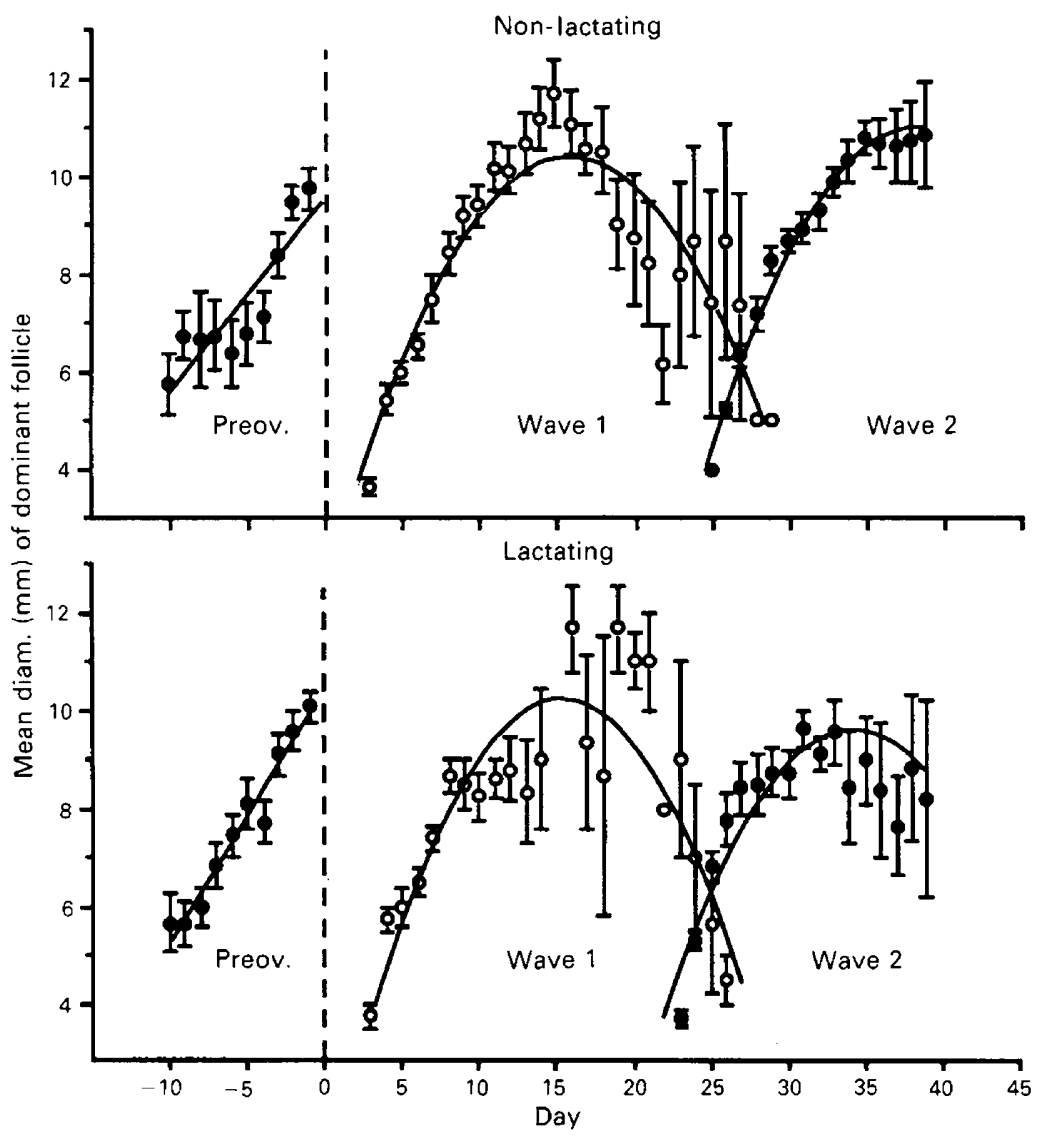

Fig. 2. Mean ( \pm s.e.m.) diameter of the dominant follicles for non-lactating and lactating llamas (data are combined for all reproductive status conditions). Origin of anovulatory waves was normalized to the mean day of first detection, and the mean profiles are shown in relation to the day of ovulation in the ovulatory groups. Effect of lactational status: not significant for preovulatory wave; $P=0.03$ for Wave 1 .

\section{Discussion}

In cattle, waves of follicular activity are characterized by the periodic emergence of a cohort of follicles. In a few days, one follicle becomes dominant and grows to a large diameter whereas the other follicles (subordinates) regress. The changing composition of waves has been studied by maintaining the day-to-day identity of individual follicles, including the subordinates (Ginther $e t$ al., 1989a). In the present study of llamas, the follicles were not individually monitored, but the 

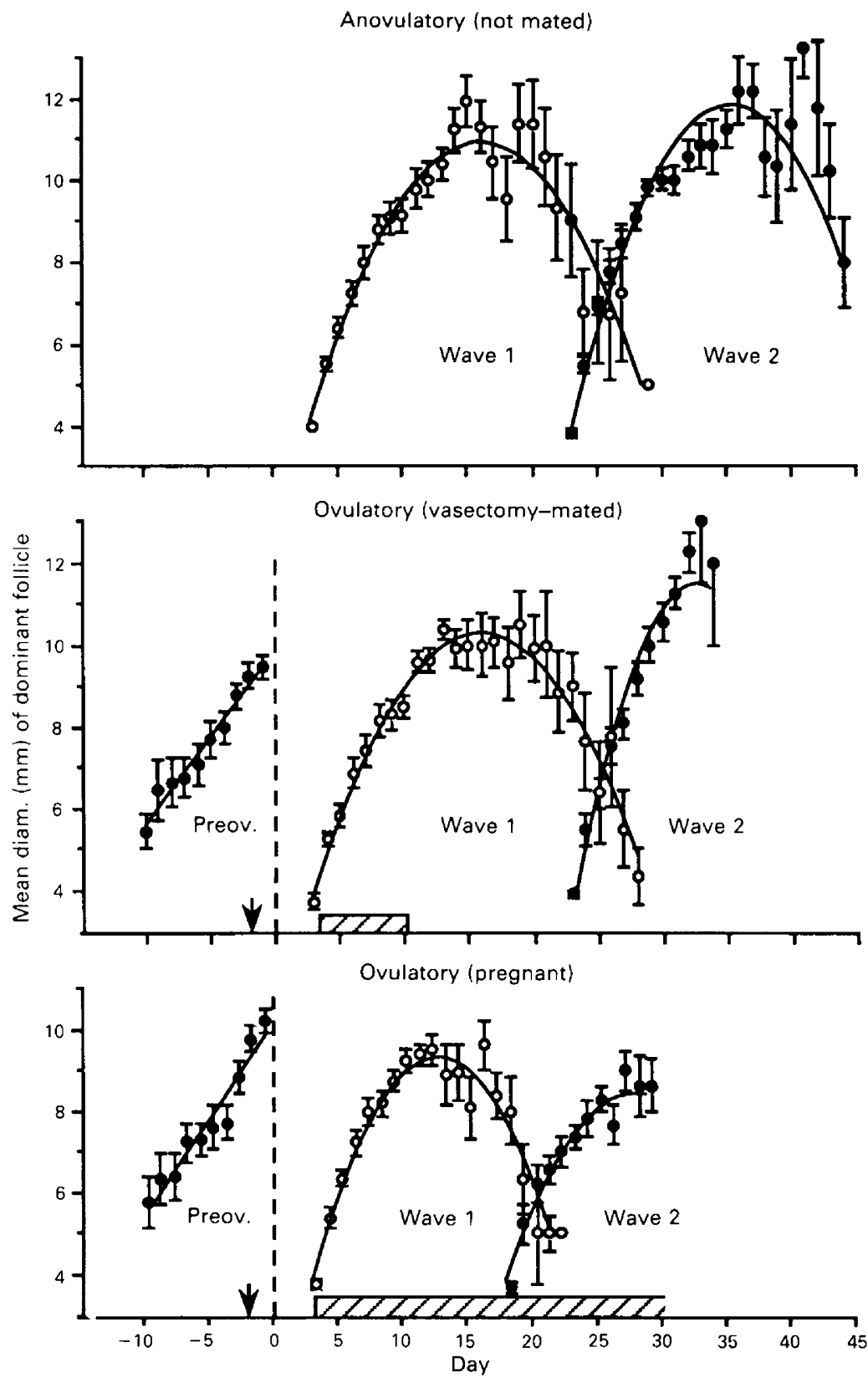

Fig. 3. Mean ( \pm s.e.m.) diameter of the dominant follicle for anovulatory, ovulatory nonpregnant, and ovulatory pregnant llamas (data for lactating and non-lactating llamas are combined). The arrow indicates the day of mating (mean, Day -2 ) and the hatched bars indicate the days of detection of the corpus luteum for the ovulatory groups. Effect of reproductive status: not significant for preovulatory wave; $P=0.03$ for Wave 1 . Mean follicle diameter for Wave 1 differed $(P<0.05)$ among each of the 3 status groups.

dominant follicle was retrospectively identifiable when successive waves occurred in opposite ovaries. Furthermore, the inverse relationship between follicle numbers and diameter of the largest follicle is consistent with a wave phenomenon. By interpretation, the onset of a wave was indicated 
by increasing numbers follicles. The subsequent reduction in numbers in association with an increase in diameter of the largest follicle presumably represented growth of a dominant follicle and regression of the remaining (subordinate) follicles. The approach used herein demonstrated the presence and some of the characteristics of follicular waves in llamas. However, further studies are needed whereby individual follicles, including the subordinates, are individually identified, especially for detailed information on the changing composition of waves.

The interval from mating to ovulation was remarkably consistent among llamas; $26 / 27$ (96\%) ovulated on the 2 nd day after mating and the remaining llama ovulated on the 3rd day after mating. This result is in agreement with the result of a previous study wherein the mean interval from mating to ovulation was 1.8 days (Adams et al., 1989). Other induced ovulators such as the rabbit and ferret also show consistency in time from mating to ovulation (9-10 h and $24-35 \mathrm{~h}$, respectively) (Ramirez \& Beyer, 1988). In a study using one-time examination of the ovaries during necropsy at 2- to 6-h intervals after mating (1-5 alpacas/time interval), ovulation had occurred by $26 \mathrm{~h}$ after mating in 3/5 alpacas (San Martin et al., 1968). Ultrasound examinations at more frequent intervals during the period $24-48 \mathrm{~h}$ after mating are needed to define better the time from mating to ovulation in llamas. The preovulatory follicle growth rate found herein $(0.8 \mathrm{~mm} / \mathrm{day})$ was also consistent with that found in the previous study $(0.7 \mathrm{~mm} /$ day; Adams et al., 1989). The growth of the preovulatory follicle was not influenced by lactational status or by type of mating (vasectomized male or intact male). For the purposes of statistical analyses, the data from Day - 10 to Day -1 best fit a simple linear regression line. However, the mean follicle growth rate from the day of mating to Day -1 was lower $(P<0.001)$ than that for Day -10 to Day $-1(0.5 v s 0.8 \mathrm{~mm} /$ day; Table 1), and large follicles $(10-12 \mathrm{~mm})$ had a slower $(P<0.02)$ growth rate than did smaller follicles $(7-9 \mathrm{~mm}$ ) from mating to ovulation (Table 2). Since the growth rate of the preovulatory follicle appeared to slow just before ovulation, perhaps the growth phase of the ovulatory follicle was similar to the growth phases of Waves 1 and 2 which followed a quadratic curve. The follicle diameter on the day before ovulation was also similar between the present study and the previous report (10.0 mm and $10.6 \mathrm{~mm}$, respectively) (Adams et al., 1989) and was unaffected by lactation or type of mating. The agreements between these 2 studies are notable since the present study was conducted during late summer in South America at an altitude of $4200 \mathrm{~m}$, whereas the previous study was conducted during the late fall in the United States at sea level. The dominant anovulatory follicle of Wave 1 was first detected retrospectively between 1 and 5 days after ovulation in all llamas and reached peak size on about Day 15, except in pregnant llamas in which it appeared to peak 2 or 3 days earlier (Figs 2 and 3).

The dominant follicle was inhibited both by lactation and pregnancy, and the effects were additive. Lactation and pregnancy were each associated with the following: (1) reduced interwave interval, (2) smaller maximum diameter of dominant follicles, and (3) less prominent day-to-day growth and regression profile of dominant follicles. Interestingly, ovulatory non-pregnant llamas had an intermediate follicular profile which was significantly different from that of anovulatory llamas and pregnant llamas. Wave 1 of anovulatory llamas was not under the influence of a corpus luteum, and Wave 1 of ovulatory non-pregnant llamas was under luteal dominance only from the time of detection (about Day 3) to about Day 10. Wave 1 of pregnant llamas was under luteal dominance from about Day 3 to beyond the end of the wave. The above observations provide a temporal rationale for the hypothesis that progesterone produced by the corpus luteum inhibits follicular growth. Further evidence was found in the observation that the maximum follicle size was significantly smaller during Wave 2 than Wave 1 only for pregnant llamas. Only pregnant llamas possessed a corpus luteum during Wave 2 and only Wave 2 of pregnant llamas was under luteal dominance for its entirety. The presence of a corpus luteum was also associated with fewer detected follicles (anovulatory group $>$ ovulatory non-pregnant group $>$ pregnant group). Pregnancy itself was not a likely cause for inhibition of follicle growth because of the difference observed between the anovulatory group and the ovulatory vasectomy-mated group-both groups were nonpregnant. The detection of the dominant follicle of the second wave was preceded by the start of 
regression of the previous dominant follicle in all llamas. Abbreviated interwave intervals occurred in pregnant llamas, perhaps due to inhibition of the dominant follicle of Wave 1 by the corpus luteum resulting in earlier regression of the dominant follicle and, hence, earlier onset of the next wave. The dominant follicle presumably was not inhibited to the same extent in non-pregnant llamas (luteal regression) as in pregnant llamas (luteal persistence); therefore, the interwave interval was not abbreviated in the former. Results of studies characterizing follicular dynamics in pregnant and non-pregnant heifers are consistent with the inhibitory effects of the corpus luteum described herein in llamas. In non-pregnant heifers which exhibited 3 waves per oestrous cycle, the mean maximum follicle diameter of the dominant follicle of Wave 1 (immature corpus luteum) was larger than that of Wave 2 (under luteal dominance for its entirety) (Ginther et al., 1989a). In pregnant heifers, the maximum diameter of the dominant follicle of Wave 1 was larger than that of any of the dominant follicles of the succeeding follicular waves (Ginther et al., 1989b).

After completion of data analysis and manuscript preparation for the present study, the results of a study on ovarian activity in alpacas were reported (Bravo \& Sumar, 1989). Based on laparoscopic examination of the ovaries at 3-, 5-, 7- or 9-day intervals, it was concluded that growth, maintenance, and regression of a follicle each required an average of 4 days (total 12 days). This contrasts with results of the present study wherein the growth and regression profile of the dominant follicle spanned 20-25 days and the interval between the emergence of successive dominant follicles was approximately 20 days for non-pregnant llamas. It was also concluded that follicular growth alternated between the 2 ovaries in alpacas. In the present study in llamas, however, alternation between left and right ovaries did not differ from equality; 21 llamas had successive dominant follicles in contralateral ovaries, and 20 in ipsilateral ovaries.

Based on the present results, one would expect to find a follicle of at least 6 or $7 \mathrm{~mm}$ at any given time during anovulatory waves (Figs 2 and 3). Whether the follicle is growing or regressing, however, would not be distinguishable on the basis of a single examination. For the purposes of mating and ovulation, it may be important that the follicle is growing and not regressing. Also, if behavioural receptivity does wax and wane, one might expect that it wanes during the regressing phase of a dominant follicle (i.e. between Days 20 and 30; Figs 2 and 3). Sexual receptivity may be expected to return immediately after luteolysis (Days 10-12) since a large ( $\geq 8 \mathrm{~mm}$ ) follicle was present at that time. In this regard, the uterus and cervix assume characteristic follicular phase morphology immediately after disappearance of the corpus luteum (Adams et al., 1989). The relationship between follicular growth and behavioural receptivity awaits more critical evaluation, as does the relationship between follicle size and the ability to ovulate in response to copulation.

Supported by the College of Agricultural and Life Sciences, University of Wisconsin-Madison, by the Veterinary Institute for Tropical and High Altitude Research, San Marcos University, Lima, Peru, and by the International Llama Association. We thank Danilo Pezo and others at the La Raya experimental station for their assistance in collecting the data; L. Kulick for technical assistance; and M. Westphal for manuscript preparation.

\section{References}

Adams, G.P., Griffin, P.G. \& Ginther, O.J. (1989) In situ morphologic dynamics of ovaries, uterus, and cervix in llamas. Biol. Reprod. 41, 55l-558.

Bravo, P. \& Sumar, J. (1989) Laparoscopic examination of the ovarian activity in alpacas. Anim. Reprod. Sci. 21, 271-281.

Chen, B.X. \& Yuen, Z.X. (1979) Reproductive pattern of the bactrian camel. In The Camelid: An All-purpose Animal,pp. $364-386$. Ed. W. R. Cochrill. Scandinavian Institute of African Studies, Uppsala.
Colby, E.D. (1986) The rabbit. In Current Therapy in Theriogenology 2, pp. 1005-1008. Ed. D. A. Morrow. W.B. Saunders Co., Philadelphia.

Cox, N.M. \& Britt, J.H. (1982) Relationships between endogenous gonadotropin-releasing hormone, gonadotropins, and follicular development after weaning in sows. Biol. Reprod. 27, 70-78.

England, B.G., Foote, W.C., Mathewes, D.H., Cordozo, A.G. \& Riera, S. (1969) Ovulation and corpus luteum function in the llama (Lama glama). J. Endocr. 45, 505-513. 
Fernandez-Baca, S., Madden, D.H.L. \& Novoa, C. (1970) Effect of different mating stimuli on induction of ovulation in the alpaca. J. Reprod. Fert. 22, 261-267.

Gill, J.L. \& Hafs, H.D. (1971) Analysis of repeated measurements of animals. J. Anim. Sci. 33, 331-336.

Ginther, O.J. (1979) Reproductive Biology of the Mare: Basic and Applied Aspects, pp. 376-378. Equiservices, Cross Plains, Wisconsin.

Ginther, O.J. \& Pierson, R.A. (1984) Ultrasonic evaluation of the reproductive tract of the mare: ovaries. $J$. eq. vet. Sci. 4, 11-16.

Ginther, O.J., Knopf, L. \& Kastelic, J.P. (1989a) Temporal associations among ovarian events in cattle during oestrous cycles with two and three follicular waves. J. Reprod. Fert. 87, 223-230.

Ginther, O.J., Knopf, L. \& Kastelic, J.P. (1989b) Ovarian follicular dynamics in heifers during early pregnancy. Biol. Reprod. 41, 247-254.

Greenwald, G.S. \& Terranova, P.F. (1988) Follicular selection and its control. In The Physiology of Reproduction, Vol. 1, pp. 387-432. Eds E. Knobil \& J. D. Neill. Raven Press, New York.

Knopf, L., Kastelic, J.P., Schallenberger, E. \& Ginther, O.J. (1989) Ovarian follicular dynamics in heifers: test of two-wave hypothesis by ultrasonically monitoring individual follicles. Dom. Anim. Endocrin. 6, $11 \mathrm{I}-119$

Musa, B.E. \& Abusineina, M.E. (1978) The estrous cycle of the camel (Camelus dromedarius). Vet. Rec. 103, $556-557$.

Novoa, C. (1970) Reproduction in Camelidae (Review). J. Reprod. Fert. 22, 3-20.

Pierson, R.A. \& Ginther, O.J. (1987) Follicular population dynamics during the estrous cycle of the mare. Anim. Reprod. Sci. 14, 219-231.
Ramirez, V.D. \& Beyer, C. (1988) The ovarian cycle of the rabbit: Its neuroendocrine control. In The Physiology of Reproduction, Vol. 2, pp. 1873-1892. Eds E. Knobil \& J. D. Neill. Raven Press, New York.

San-Martin, M., Copaira, M., Zunigra, J., Rodreguez, R., Bustinza, G. \& Acosta, L. (1968) Aspects of reproduction in the alpaca. $J$. Reprod. Fert. 16, 395-399.

SAS User's Guide. (1985) Statistics. Version 5 Edition. SAS Institute Inc., Cary, NC.

Savio, J.D., Keenan, L., Boland, M.P. \& Roche, J.F. (1988) Pattern of growth of dominant follicles during the oestrous cycle in heifers. J. Reprod. Fert. 83, 663-671.

Schmidt, P.M., Chakraborty, P.K. \& Wildt, D.E. (1983) Ovarian activity, circulating hormones and sexual behavior in the cat. II. Relationships during pregnancy, parturition, lactation and the postpartum estrus. Biol. Reprod. 28, 657-671.

Shalash, M.R. \& Nawito, M. (1964) Some reproductive aspects of the female camel. Proc. 5th Int. Congr. Anim. Reprod. \& A.I., Trento 1-2, pp. 263-273.

Short, R.E., Bellows, R.A., Moody, E.L. \& Howland, B.E. (1972) Effects of suckling and mastectomy on bovine postpartum reproduction. J. Anim. Sci. 34, 70-74.

Sirois, J. \& Fortune, J.E. (1988) Ovarian follicular dynamics during the estrous cycle in heifers monitored by real-time ultrasonography. Biol. Reprod. 39, 308-317.

Sirois, J., Ball, B.A. \& Fortune, J.E. (1989) Patterns of growth and regression of ovarian follicles during the oestrous cycle and after hemiovariectomy in mares. Equine vet. J., Suppl. 8, 43-48.

Received 7 March 1990 